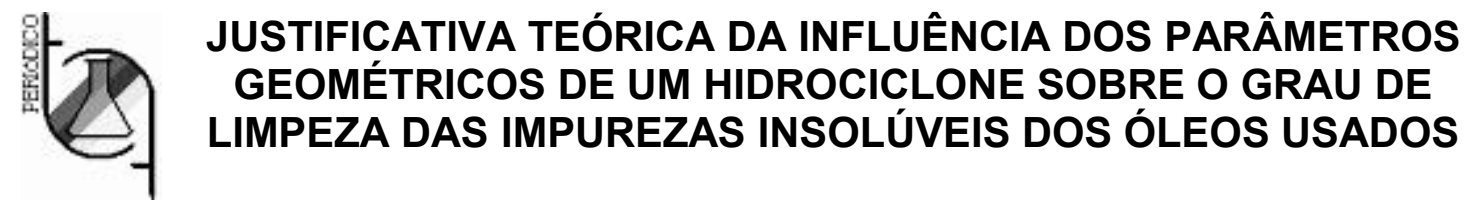

\title{
THEORETICAL JUSTIFICATION OF INFLUENCE OF GEOMETRICAL PARAMETERS OF A HYDROCYCLONE UPON THE DEGREE OF CLEANING OF THE USED OILS FROM THE INSOLUBLE IMPURITIES
}

\section{ТЕОРЕТИЧЕСКОЕ ОБОСНОВАНИЕ ВЛИЯНИЯ ГЕОМЕТРИЧЕСКИХ ПАРАМЕТРОВ ГИДРОЦИКЛОНА НА СТЕПЕНЬ ОЧИСТКИ ОТРАБОТАННЫХ МАСЕЛ ОТ НЕРАСТВОРИМЫХ ПРИМЕСЕЙ}

\author{
KHOKHLOV, Alexey L..$^{1 *}$; GLUSHCHENKO, Andrey A. ${ }^{2}$; SALAKHUTDINOV, IImas R. ${ }^{3}$; \\ PROSHKIN, Evgeny N. ${ }^{4}$; MARIN, Dmitry M. ${ }^{5}$
}

1,2,3,4,5 Ulyanovsk State Agrarian University named after P.A. Stolypin, Department of Operation of Mobile Machines and Technological Equipment, 1 Novy Venets Boulevard, zip code 432017, Ulyanovsk - Russian

Federation

(phone: +89278280897)

* Corresponding author

e-mail: chochlov.73@mail.ru

Received 01 December 2017; received in revised form 09 February 2018; accepted 24 May 2018

\begin{abstract}
RESUMO
A questão imediata do problema investigado está ligada à necessidade de desenvolvimento de tecnologias ambientalmente corretas para a remoção das impurezas insolúveis dos óleos minerais usados. O objetivo deste artigo é descrever a investigação teórica da influência dos parâmetros geométricos do hidrociclone cilíndrico sobre o grau de limpeza das impurezas insolúveis e das partículas do desgaste metálicas dos óleos minerais usados de alta viscosidade. A principal abordagem para a investigação deste problema é a seguinte: analisar o comportamento de uma partícula insolúvel na corrente de óleo sob a influência das forças que atuam sobre esta partícula. Tal análise permite determinar os parâmetros geométricos e operacionais do hidrociclone cilíndrico, que exercem maior influência sobre o grau de limpeza dos óleos. Este artigo apresenta a justificativa teórica da influência dos parâmetros geométricos do hidrociclone cilíndrico sobre o grau de limpeza do óleo usado. Além disso, descreve o critério de separação, que permite determinar as dimensões ótimas do hidrociclone e avaliar comparativamente os hidrociclones com diferentes parâmetros geométricos em relação à eficiência de limpeza das impurezas insolúveis de óleos.
\end{abstract}

Palavras-chave: critério de separação, unidade hidrociclone, óleo do motor, taxa de ajuste, separação.

\section{ABSTRACT}

The immediacy of the problem under investigation is connected with the need for the development of the environmentally friendly technologies for cleaning of the used mineral oils from the insoluble impurities. The purpose of this article is to describe the theoretical investigation of the influence of the geometrical parameters of the cylindroconical hydrocyclone upon the degree of cleaning of the used high-viscosity mineral oils from the insoluble impurities and from the wear metal particles. The main approach to the investigation of this problem is as follows: analysis of the behavior of an insoluble particle in the stream of oil under the influence of the forces, which act upon the particle. Such analysis makes it possible to determine the geometrical and operating parameters of the cylindroconical hydrocyclone, which exert the greatest influence upon the degree of cleaning of oils. This article presents the theoretical justification of influence of the geometrical parameters of the cylindroconical hydrocyclone upon the degree of cleaning of the used oil. In addition, this article describes the separation criterion, which makes it possible to determine optimum dimensions of the hydrocyclone and perform a comparative assessment of the hydrocyclones with different geometrical parameters in respect of the 
efficiency of cleaning of oils from the insoluble impurities.

Keywords: separation criterion, hydrocyclone unit, motor oil, the rate of setting, separation.

\section{АННОТАЦИЯ}

Актуальность исследуемой проблемы обусловлена потребностью в разработке экологически безопасных технологий и технических средств очистки отработанных минеральных масел. Цель статьи заключается в теоретическом исследовании влияния геометрических параметров цилиндроконического гидроциклона на степень очистки отработанных высоковязких минеральных масел от нерастворимых примесей и продуктов износа. Ведущим подходом к исследованию данной проблемы является рассмотрение поведения нерастворимой частицы в потоке масла под воздействием действующих на нее сил, позволяющее выявить геометрические и режимные параметры цилиндроконического гидроциклона оказывающие наибольшее влияние на степень очистки масла. Результаты исследования: В статье представлено теоретическое обоснование влияния геометрических пара-метров цилиндроконического гидроциклона на степень очистки отработанного масла, предложен критерий сепарации, позволяющий не только определять оптимальные размеры гидроциклона, но и проводить сравни-тельную оценку гидроциклонов с различными геометрическими параметра по эффективности очистки масел от нерастворимых примесей.

Ключевые слова: очистка масла, критерий сепарации, гидроциклон, геометрические параметры.

\section{INTRODUCTION}

One of the most common methods is based on the principle of cleaning and drying of oils and various technical liquids in the fields of forces (Bahadori, 2016; Wang et al., 2016). For this purpose, various centrifugal machines and separators are widely used. A critical weakness of all these centrifugal machines and separators is connected with: degradation of the quality of the oil cleaning in the case of decrease of the oil temperature; the complexity of these units; as well as their low reliability. Recently, hydrocyclone units are used for cleaning of various liquids more frequently (Glushchenko, 2009). They ensure removal of solid particles from the stream of the oil to be cleaned under the influence of the centrifugal forces. Hydrocyclone units are characterized as the facilities, which have higher reliability (because of they have no rotating parts), as well as which are characterized by low cost and easy maintenance. They can be installed in various places out of the vertical. At the present time, many research-anddevelopment centers perform the work with the purpose of application of the hydrocyclone units for cleaning of various liquids (Glushchenko, 2009; Glushchenko and Zeynetdinov, 2011).

Hydrocyclone (Figure 1) is the unit of equipment, which consists of the cylindrical part 1 , broad bottom of which is connected with the conical section 7 . The intermediate overflow chamber 3 , which is equipped with the branch tube for removal of the low-weight products, is fixed on the upper section of the cylindrical part. Diaphragm 6 is installed between the cylindrical section and the overflow chamber, while replaceable necks 8 are fixed in the lower part of the cone (Abe, 2017; Harbaoui et al., 2018).

A hydrocyclone for cleaning of the used motor oil works as follows (Farias, 2011). Contaminated oil is transported tangentially under pressure into the cylindrical section of the body 1 through the facility 3 for admission of the oil to be cleaned. Then the oil acquires rotational motion and moves into the conical section of the body 1 . The substantial centrifugal forces (which exceed the gravity force) are created in this process, and the heavier fractions of the oil to be cleaned move downward under the action of these forces from the axis of the hydrocyclone to the walls of the body 1 along the spiral trajectory. Then heavy fractions are removed from the hydrocyclone through the overflow branch tube 7 . The easier fractions move upward inside the diaphragm 2 within the internal spiral stream. Later on, they go into the internal cavity of the cover 5 . Then they are removed outward through the facility for removal of the cleaned oil 4.

Efficiency of cleaning of the used motor oil is increased at the expense of the fact that the facility for admission of the oil to be cleaned (this facility is manufactured in the form of the branch tube (which has the rectangular cross-section) and installed tangentially in the upper section of the body with the slope to the horizontal plane) 
ensures laminarity of the stream of the oil to be cleaned in the course of its rotational movement along the internal wall of the body (Lua et al., 2018). The diaphragm, which is installed under the cover along the axis of the body and is equipped with the outer protuberance in the form of the ring, ensures high quality of the process of separation of the oil by fractions. In addition, the facility for removal of the cleaned oil, which is installed tangentially to the cover, increases the efficiency of the oil cleaning at the expense of a decrease of the resistance of motion of the cleaned oil in the course of the oil movement from the hydrocyclone.

\section{MATERIALS AND METHODS}

It is possible to present the process of separation of the used oil by fractions within the hydrocyclone as follows (Mamalis, 2018). The forces that act upon a particle in the stream of a liquid within the hydrocyclone (Figure 2): centrifugal force $P_{c}$ (or $\mathrm{P}_{4}$ in formulas), which pushes the particle back to the periphery; radial force $P_{r}$, which is created due to action of the radial stream of liquid and which is directed to the axis of the unit of equipment; Coriolis force $P_{\text {Coriolis }}$ (or $P_{K}$ in formulas) which moves the particle in the peripheral direction in respect of the stream; force of the medium resistance $P_{\text {Res }}$ (or $P_{c}$ in formulas), which prevents deposition of particles; inertial force $P_{\text {Inert }}$ (or $P_{n}$ in formulas), which is created due to changes in the rate of deposition.

If we will take into consideration small dimensions of a particle and assume that such particle is captured by the stream into rotational motion with angular velocity $\omega$, then the main force, which acts upon it, is the centrifugal force (Equation1) (Shestov, 1967): where $m$ - mass of a particle, $\mathrm{kg} ; \omega$ - angular velocity of rotation, $\mathrm{s}^{-1}$; $r$ - radius of rotation of a particle, $\mathrm{m} ; \delta$ - diameter of a particle, $\mathrm{m} ; \rho$ - density of a particle, $\mathrm{kg} / \mathrm{m}^{3}$; $v$ - linear local velocity of the stream, $\mathrm{m} / \mathrm{s}$.

In the case of helical movement of the liquid stream within the hydrocyclone, one may observe the Stokes mode (i.e. laminar mode) of deposition of the particles, which are present in the oil stream, and this mode ensures separation of these particles by phases (Prikhna et al., 2018; Balo, 2015). Therefore, if we will take into account both action of the centrifugal force $P_{c}$ and action of the medium resistance force $P_{\text {Res, }}$ then (taking into account the medium resistance force) it follows from the Equation2: where $\rho_{\text {liq }}$ density of liquid, $\mathrm{kg} / \mathrm{m}^{3} ; v_{c}$ - rate of separation (removal of solid particles of the insoluble impurities from the oil), $\mathrm{m} / \mathrm{s} ; \mu$ - kinematic viscosity of the oil to be cleaned, $\mathrm{m}^{2} / \mathrm{s}$. Then Equation 3.

The inertial force $P_{\text {Inert }}$ is caused by the change of the relative velocity of a particle in the stream of the relevant medium in the course of reconstruction of the velocity profile of a particle at the input to the cylindrical section of the hydrocyclone. A stream of a liquid goes into the hydrocyclone with initial velocity $v_{\text {init }}$ (liquid velocity in the input branch tube of the hydrocyclone); then velocity profile changes in the line of 1-1 (Figure 2). In the course of movement of the liquid into the curved channel of the input branch tube, the velocity profile $v_{\text {init }}$ changes (Figure 2, line 2-2) and distribution of the liquid velocity over the cross-section of the input channel corresponds to the law of change of the tangential velocity depending on of radius (Equation 4) where $n$ - exponent of power (Shestov, 1967).

The distribution of liquid velocity within the curved channel (line 2-2, Figure 2) will be described by the following dependence (Equation 5 ): where $R_{2}$ - outer radius of the liquid stream, which is equal to the radius of the hydrocyclone $R_{2}=R_{\text {Hydro }}, \mathrm{m} ; R_{1}-$ internal radius of the liquid stream within the hydrocyclone, $\mathrm{m}$.

Having substituted (Equation5) into (Equation3), we obtain (Equation 6). Having accepted the average value of radius $r$ as the current radius $r$, (Equation 7)we obtain the generalized dependence, which characterizes minimum diameter of the particles that are deposited (Equation 8), where $D$ - diameter of the hydrocyclone $D=2 R_{2}, \mathrm{~m}$.

However, utilization of the average value of radius will make it possible to determine the only diameter of those particles, which are present at this radius, but it will not let to determine actual diameter of the particle that is deposited. In order to solve this problem, it is necessary to utilize the value of the radius of the zero vertical velocity.

\section{RESULTS AND DISCUSSION:}

\subsection{Calculation of the axial velocity and coordinates of a particle}


If we assume that there is no vertical influence upon a particle in the stream within the hydrocyclone, then each particle will be in the suspension state at the certain distance from the center of rotation, that is, at the distance, where the centrifugal force will be equal to the radial force $P_{\text {Res }}=P_{r}$. The heavier particles will be situated nearer to the periphery of the hydrocyclone, while easy particles will be situated in the hydrocyclone center (Coleman et al., 2018). In the course of movement of each group of particles, which are present in the oil stream, they will create the curved surface within the internal conical cavity of the hydrocyclone (Figure 3).

Points of the zero vertical velocity (that is, boundaries of variation of signs of the vertical velocity) create a curved surface as well. Intersection (or coincidence) of the plane of the vertical velocity with the plane of any group of particles will determine the grain particle size: therefore, the biggest particles will go to the discharge line, while the least particles will go to the cleaned stream (Glushchenko, 2006).

In order to determine the radius of the zero surface, it is necessary to determine the axial velocity of movement of a particle in the stream within the hydrocyclone. In order to calculate axial velocity, we will use the following formula (Glushchenko, 2009; Glushchenko and Zeynetdinov, 2011; Shestov, 1967) (Equation 9 - Equation10), where $\Gamma=$ const - velocity circulation per unit of the toroid height, $\mathrm{m}^{2} / \mathrm{s} ; R_{o}$ radius of the surface of the zero axial velocities at the boundary of cylindrical and conical sections of the hydrocyclone, $\mathrm{m}$ (Equation11). Where $R_{\Gamma}$ - radius of the hydrocyclone, $\mathrm{m} ; r_{0}-$ radius of the air column $\left(r_{o}=0.606 r_{c}\right), m ; r_{c}-$ radius of removal of the cleaned oil, $\mathrm{m} ; r_{\Pi^{-}}$radius of the overflow branch tube, $\mathrm{m} ; \alpha_{1}$ - angle of conicity of the hydrocyclone, degrees; $\beta$ - angle of slope or angle of displacement of a point in the course of movement within the vortex layer by height (h-z), degrees; $h$ - distance of the analysed ring cross-section from the point of beginning of the vortex layer (that is, from the upper cover of cylindrical section of the hydrocyclone), $\mathrm{m} ; \mathrm{H}$ height of the conical section of the hydrocyclone, $\mathrm{m} ; H_{1}$ - height of the cylindrical section of the hydrocyclone, $\mathrm{m}$.

Tangential velocity of a particle (Equation12 - Equation13) where $C$ - constant value, which characterises dependence of productivity from the hydrocyclone height; $r_{H}-$ outer diameter of the analysed ring cross-section, $\mathrm{m} ; R$ and $z$ - coordinates of the point, for which velocity is calculated, $\mathrm{m} ; v_{t}$ - tangential velocity of the particle, $\mathrm{m} / \mathrm{s} ; d h-$ height of the analysed ring, $\mathrm{m}$;

Axial velocity of a particle (Equation14). In order to determine interconnections in the criterial form in accordance with the regression model of the dependence between radius of the zero surface $R_{o}$ and parameters of the hydrocyclone, we have to compose relevant matrix and assume the following independent variables: height of the working section of the hydrocyclone $\mathrm{H}+\mathrm{H}_{1}$; coordinate of the particle in respect to the radius of the hydrocyclone $R$; coordinate of the particle in respect to the height of the hydrocyclone $\mathrm{H}+$ $H_{1}$; distance to the analysed cross-section $h$ of the conical section of the hydrocyclone; diameter of the cross-section $d$, and axial velocity $v_{z}$ (Table 1)

Table 1. Matrix for calculation of interconnections in the criterial form

The regression equation will have the following form (Equation15), where $a_{0}, a_{1}, \ldots a_{n^{-}}$ coefficients of regression for the predetermined parameters of the hydrocyclone; $X_{1}, X_{2}, \ldots X_{n}-$

\begin{tabular}{lllllll}
\hline$R_{0}$ & $\begin{array}{l}H+H \\
1\end{array}$ & $R$ & $z$ & $h$ & $d$ & $V_{z}$ \\
\hline-1 & -1 & -1 & -1 & -1 & -1 & -1 \\
-1 & -1 & -1 & -1 & -1 & -1 & 0 \\
-1 & -1 & -1 & -1 & -1 & 0 & 1 \\
-1 & -1 & -1 & -1 & 0 & 1 & 1 \\
-1 & -1 & -1 & 0 & 1 & 1 & 1 \\
-1 & -1 & 0 & 1 & 1 & 1 & 1 \\
\hline
\end{tabular}

parameters of the hydrocyclone.

Having preliminary information concerning the influence of the above-listed parameters of the hydrocyclone upon the radius of the surface of the zero axial velocity, we will present relevant functional relationship in general form (Equation16).

In order to calculate coefficients, we have to determine change of the axial velocity of the particle and coordinates of the particle, which moves in the vortex stream of the hydrocyclone, in three points of the cross-section by height and ten points in respect to the radius of the hydrocyclone (Weiss et al., 2015). In this case, zcoordinate of the particle will accept certain numerical values depending on the diameter of the cross-section, as well as depending on the position of this particle by the height of the 
hydrocyclone. Having accepted the condition that $z$-coordinate is a numerical varying value, we obtain (Equation 17). That is, only $R$ (coordinate of the analyzed point) will change. Having completed the calculation of the position of the point, we obtain a certain quantity (a row) of numerical values of the main parameters.

\subsection{Calculation of axial velocity of a particle within the stream}

Having completed the calculation of the changing coordinate of the position of the particle within the stream in the hydrocyclone, as well as the calculation of the regression coefficients, we obtain the quadratic equation of axial velocity of the particle within the stream. Having substituted the boundary values of the variables, which were calculated for these specific conditions $(h=0.01-$ $0.18 \mathrm{~m}, R_{0}=0.02 \mathrm{~m}, r_{0}=0.017 \mathrm{~m}, \alpha=5^{\circ} 2^{\prime}, H+H_{0}=$ $0.302 \mathrm{~m}, \beta=100-120^{\circ}, R=0.018-0.046 \mathrm{~m}$ ), and having performed proper transformation of this equation, we obtain theoretical dependence between the axial velocity of a particle within the stream and constructional/technological parameters of the hydrocyclone depending on the necessary values of the oil cleaning quality (Equation18).

In order to ensure calculation of radius of the boundary layer (of the zero surface), we have obtained the dependence of relevant parameters of the hydrocyclone (radius $R$ and height (as a function of productivity) $C$ ) from $z$-coordinate of the particle within the stream of the oil to be cleaned (Equation19). Now we substitute equation (17) for the radius of the zero surface of axial velocity into expression (6), provided that in this case, we will also substitute the value of the hydrocyclone diameter $D$ by the value of the radius of the zero surface $2 R_{o}$. Then we obtain the dimension of the particles, which are separated at the certain radius of the hydrocyclone (Equation20).

The dependence, which we have obtained, demonstrates obviously connection of each value of the radical expression with a dimension of the particles, which are separated in the spiral stream of the hydrocyclone. In this case, the dimension of the separated particles will increase in accordance with the increase of radius of the zero surface. Therefore, in order to collect the finely-dispersed particles, it is necessary to use the hydrocyclones, which have small diameters. The increase of initial velocity of the stream of the oil to be cleaned $v_{\text {init }}$ (within input branch tube of the hydrocyclone) helps to separate the smaller particles as well.

It is not always possible to use the Equation 18 for calculation of the minimum dimension of the separated particle for practical purposes, because of this expression includes an unknown value - the rate of separation $v_{\mathrm{c}}$.

In order to determine the rate of separation, we will assume that the particle, which has entered into the hydrocyclone near the input branch tube (at radius $R_{1}$ ), must be deposited on the wall of the hydrocyclone during the period of movement through the cylindroconical section of the hydrocyclone.

If we assume that (taking into account the nature of the movement of particles) the hydrocyclone works in the mode of ideal displacement, then the time of deposition of a particle(Equation21). Where $V_{2}$ - the volume of the cylindroconical section of the hydrocyclone, $\mathrm{m}^{3}$; Qhydro- productivity of the hydrocyclone, $\mathrm{m}^{3} / \mathrm{hr}$; $H$ - height of the cylindroconical section of the hydrocyclone, $\mathrm{m}$.

Because of separation of particles is ensured at the radius $R_{0}$, we can substitute $R_{2}-R_{1}$ by $R_{0}$ and obtain (Equation22). In this case, the rate of setting of a particle (Equation23). Three values are essential for separation of particles within the hydrocyclone: the rate of separation $v_{\mathrm{c}}$, the thickness of the deposition layer and time of presence of a particle within the hydrocyclone $\tau$.

With the help of these three values, it is possible to create the parameter, which will be the separation criterion and which will determine the quantity of the separated particles from the stream of the oil to be cleaned(Equation24), where $\lambda$ - the thickness of the deposition layer, $m$. Because of the thickness of the deposition layer is determined by boundary values of radiuses $R_{\text {Hydro }}-R_{o}$, then (Equation25), where $R_{\text {Hydro }}-$ radius of the hydrocyclone, $\mathrm{m}$.

Because of quality of cleaning determines the quantity of the deposited impurities, we may substitute volume of the supplied oil by the amount of impurities in the oil to be cleaned. Having made such substitution and having entered value $v_{\mathrm{c}}$ into the (Equation22), we obtain (Equation26), where $G_{2}$ - quantity of impurities in the oil to be cleaned, $\mathrm{kg}$.

In this case, it is possible to determine the quality of cleaning in the hydrocyclone as carry- 
over of particles through the overflow opening presented as a percentage share of the total quantity of particles, which go into the hydrocyclone along with the oil to be cleaned (Equation27).

Therefore, quality of the oil cleaning will be determined by geometrical parameters of the hydrocyclone, as well as by the time of presence of a particle within the hydrocyclone (this time depends on the mode of separation).

In order to confirm the correctness of the obtained theoretical conclusions, comparative laboratory investigations were performed with the purpose of finding the efficiency of cleaning of the used mineral oil from the insoluble impurities with the help of two hydrocyclones (reference and control hydrocyclones). The hydrocyclone, which was manufactured in accordance with the method that is recommended by many research workers for calculation of geometrical parameters of hydrocyclones (Shestov, 1967), was used as the control hydrocyclone.

In the course of these investigations, it was established that reference cylindroconical hydrocyclone, geometrical parameters of which were determined in accordance with the obtained theoretical conclusions, ensures the best degree of cleaning $(88.4 \%$ at the following parameters: productivity of the process $3 \ldots 5 \mathrm{t} / \mathrm{hr}$; pressure of the input stream $P=0.04 \mathrm{MPa}$; depth of immersion of the separating diaphragm of the hydrocyclone $H=136.8 \mathrm{~mm}$ ) as compared with the degree of cleaning at the level of $21.6 \%$, which is ensured by the typical hydrocyclone.

\section{CONCLUSIONS:}

The analysis of scientific publications has shown that up to the present day technological calculations of hydrocyclones were restricted by calculations of productivity of the hydrocyclone, which works at optimum geometrical parameters that correspond to the maximum separation of impurities, which are present in the liquid to be cleaned. In order to determine productivity, many authors have proposed a number of formulas. In result of the performed analysis, it was established that all these formulas, which are already known, were obtained on the basis of three prerequisites:

- hydrocyclone is analyzed as a local resistance of a pipeline;
- the process of liquid outflow from the hydrocyclone is considered as the liquid outflow from the submerged orifice/opening;

- the law of liquid outflow from the hydrocyclone is similar to the laws, which were obtained for the liquid outflow through the spillway, which is created by edges of the upper overflow orifice.

What is more, these formulas are in essence identical regardless of the selection of prerequisites. Calculation of main dimensions of hydrocyclones was based on the method, which was developed by R. N. Shestov (Year). In the case of implementation of this method, a hydrocyclone made it possible to ensure finer cleaning of the used mineral oil. Authors found out, it was difficult to select a hydrocyclone having any desired degree of cleaning. Therefore, it is more useful to calculate geometrical dimensions of the hydrocyclone, if take into account the desired degree of cleaning instead of the hydrocyclone productivity. The abovepresented method of calculation of geometrical dimensions of the hydrocyclone is based on the desired degree of cleaning.

Therefore, the quality of the oil cleaning from insoluble impurities was determined by geometrical parameters of the hydrocyclone: radius $\mathrm{RHydro}$, the height of the cylindroconical section $\mathrm{H}$ and time of presence of a particle within the hydrocyclone (this time depends on the mode of separation).

\section{RECOMMENDATIONS:}

The theoretical laws of change of the axial velocity of a particle within the hydrocyclone, which were obtained, making it possible to: determine interconnection between the degree of cleaning and depth of immersion of the separating diaphragm into the stream of oil, as well as between pressure of the input oil stream; simulate process of separation of the insoluble impurities from high-viscosity liquids within the hydrocyclone; determine design parameters and technological modes of operation of hydrocyclones in order to ensure the desired degree of cleaning of the used oil from insoluble impurities. Results of these investigations, as well as the method, which was developed, may be used by research, development, and project organisations in the course of development of new technological equipment, as well as in the 
course of improvement of the already existing technological facilities for cleaning of the used mineral oils and for recovery of operational properties of such oils by the enterprises of the oil-processing industry and agro-industrial complex in order to satisfy their own needs in mineral oils. In addition, these results and this method may be used by institutions of higher education (that is, by universities and colleges) in their educational processes in the course of studying technologies and technical facilities for recovery of operational properties of the used lubricating mineral oils.

\section{REFERENCES:}

1. Abe, H. J. Fluid Mech, 2017, 833, 563-598.

2. Bahadori, A.Essentials of Oil and Gas Utilities. London: Gulf Professional Publishing, 2016.

3. Balo, F. Energy and Buildings, 2015, 86, 161175.

4. Coleman, G. N., Rumsey, C. L., Spalart, P. R. Journal of Fluid Mechanics, 2018, 847, 28-70

5. Farias, F, Souza, J, Lima, W., Macêdo, A, Neto, S, Lima, A. Int. Jnl. of Multiphysics, 2011, 5 (3), 187-202.

6. Glushchenko, A. A. Methods of regeneration of used oils. Agrarian science and education in the implementation of the national project "Development of the AIC": the materials of the All-Russian Scientific and Practical Conference, Ulyanovsk: P. A. Stolypin Ulyanovsk State Agricultural University, 2006.

7. Glushchenko, A.A., Bulletin of the Moscow State University of International Relations, 2009, 3,82-85.

8. Glushchenko, A. A., Zeynetdinov, R. A. Bulletin of Ulyanovsk State Agricultural Academy, 2011, 1, 84-88

9. Harbaoui, I., Casimir, J. B., Khadimallah, M. A., Chafra, M. International Journal of Mechanical Sciences, 2018, 140, 37-50.

10. Lua, K.B., Hao, Lu, Lim, T. T. Journal of Fluids and Structures, 2018, 78, 36-51.

11. Mamalis, A. G. Int. Jnl. of Multiphysics, 2018, 12 (1), 27-40.

12. Prikhna, T., Eisterer, M., Mamalis, A. G., Romaka, V., Sokolovsky, V., Kozyrev, A., Karpets, M., Moshchil, V., Sverdun, V., Ponomaryov, S. Materials Science Forum,
2018, 915, 65- 70.

13. Shestov, R. N. Hydrocyclones, Leningrad: Mashinostroenie, 1967.

14. Wang, X., Yu, J., Sun, G., Ding, B. Materials Today, 2016, 19 (7), 403-414.

15. Weiss, J., Mohammed-Taifour, A., Schwaab, Q. AIAA J., 2015, 53 (9), 2634-2645. 


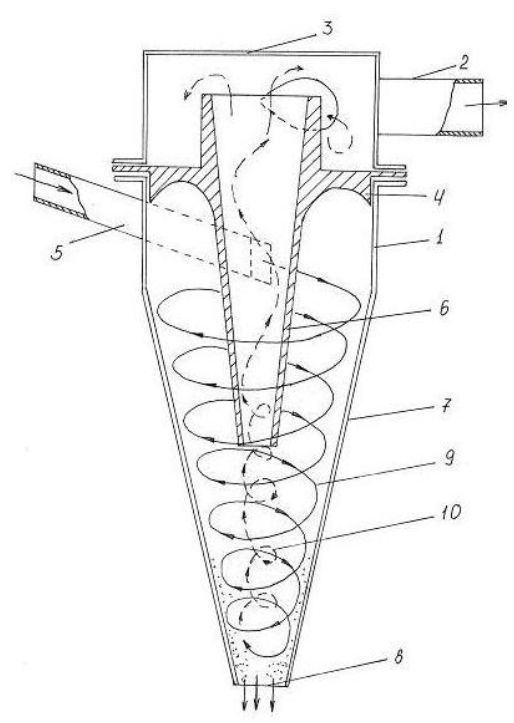

Figure 1. Diagram of the hydrocyclone (please see explanations in the text)

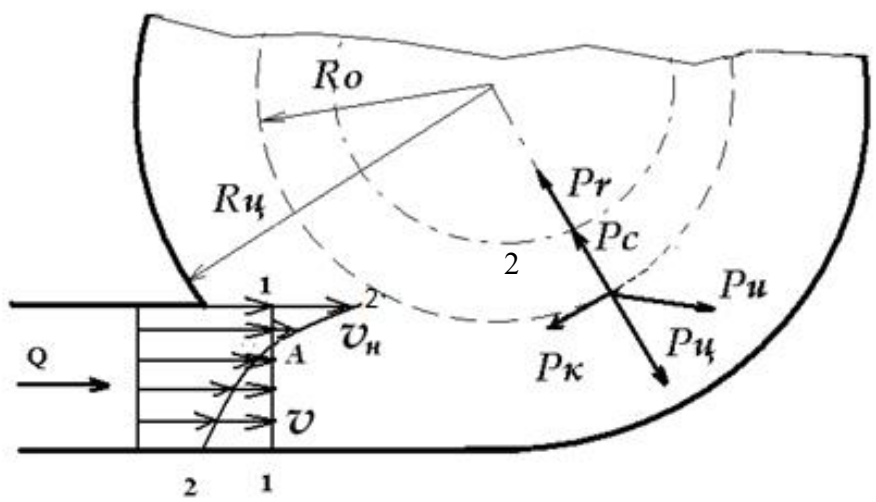

Figure 2. The forces, which act upon the particle in the spiral stream within the hydrocyclone

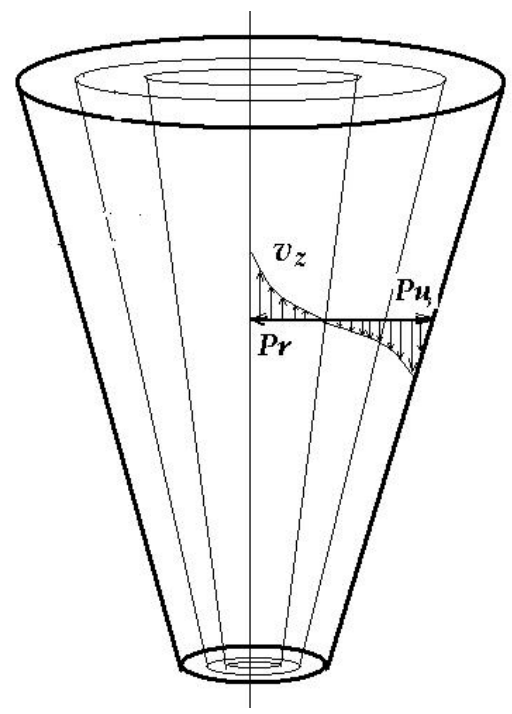

Figure 3. Diagram of surfaces of particles in the stream within the hydrocyclone 


$$
\begin{aligned}
& P_{u}=m \cdot \omega^{2} \cdot r=\frac{\pi \cdot \delta^{2} \cdot \rho \cdot \omega^{2} \cdot r}{6}=\frac{\pi \cdot \delta^{2} \cdot \rho \cdot v^{2}}{6 r}, \\
& \frac{\pi \delta_{u}^{2} \rho_{u} v^{2}}{6 r}=\frac{24 \mu}{v_{c} \delta_{u} \rho_{\curvearrowright c}} \frac{\pi \delta_{u}^{2}}{4} \frac{\rho_{\Im c} v_{c}^{2}}{2} \\
& \frac{v^{2}}{r}=\frac{18 v_{c} \mu}{\delta_{u}^{2} \rho_{u}} . \\
& v r^{n}=\text { const } \\
& v=\frac{v_{H}\left(R_{2}-R_{1}\right)}{r \ln \frac{R_{2}}{R_{1}}}, \\
& \frac{v_{\mu}\left(R_{2}-R_{1}\right)^{2}}{r^{3}\left(\ln \frac{R_{2}}{R_{1}}\right)^{2}}=\frac{18 v_{c} \mu}{\delta_{u}^{2} \rho_{u}} \\
& r_{c p}=\frac{R_{2}+R_{1}}{2} \\
& \delta_{u_{\text {min }}}=\sqrt{\frac{18 v_{c} \mu D}{2,5 v_{H}^{2} \rho_{u}}}, \\
& V_{z}=\frac{\Gamma}{4 \pi \cos \frac{\alpha_{1}}{2}} \int_{0}^{H+H 1} d h \int_{0}^{2 \pi} \frac{\left(R o-h t g \frac{\alpha_{1}}{2}\right)-\left(R o-h t g \frac{\alpha_{1}}{2}\right) R \cos \beta}{\left[(h-z)^{2}+\left(R o-h t g \frac{\alpha_{1}}{2}\right)^{2}+R^{2}-2 R \cos \beta\left(R o-h t g \frac{\alpha_{1}}{2}\right)\right]^{3 / 2}} d \beta, \\
& \Gamma=2 \pi r v_{t} ; \\
& R_{O}=\frac{r_{o}}{r_{c}+r_{n}}\left(R_{\Gamma}+H \operatorname{tg} \frac{\alpha}{2}\right), \\
& V_{t}=C r_{0} \int_{0}^{H+H 1} d h \int_{0}^{2 \pi} \frac{R-r_{H} \cos \beta}{\left[(h-z)^{2}+r_{H}+R^{2}-2 r_{H} \cos \beta\right]\left(r_{H}^{2}+R^{2}-2 R_{0} \cos \beta\right)} d \beta, \\
& \operatorname{tg} \frac{\alpha_{1}}{2}=\frac{r_{o}}{r_{c}+r_{n}} \operatorname{tg} \frac{\alpha}{2},
\end{aligned}
$$




$$
\begin{aligned}
& v_{z}=\frac{2 \pi r C r_{o}}{4 \pi \cos \frac{\alpha_{1}}{2}} \int_{0}^{H+H_{1}} \int_{0}^{2 \pi} \frac{R-r_{o} \cos \beta}{\left[(h-z)^{2}+r_{o}^{2}+R^{2}-2 r_{o} \cos \beta\right]\left(r_{o}+R^{2}-2 R_{o} \cos \beta\right)} \times \\
& \times \int_{0}^{H+H_{1}} \int_{0}^{2 \pi} \frac{\left[\left(R_{o}-h \operatorname{tg} \frac{\alpha_{1}}{2}\right)^{2}-\left(R_{o}-h \operatorname{tg} \frac{\alpha_{1}}{2}\right) R \cos \beta\right]}{\left[(h-z)^{2}+\left(R_{o}-h \operatorname{tg} \frac{\alpha}{2}\right)^{2}+R^{2}-2 R \cos \beta\left(R_{o}-h t g \frac{\alpha_{1}}{2}\right)\right]^{\frac{3}{2}}} d \beta d h \\
& R_{o}=a_{o}+a_{1} X_{1}+a_{2} X_{2}+\ldots+a_{n} X_{n}=0 \\
& R_{o}=f(\alpha, R, h, z, d) . \\
& r_{o}, R_{o}, \alpha, \beta, r, h=\text { const; } \\
& v_{z}=y=(-244,524-30)-19769,382 r-138,852 z+31610,804 C+ \\
& +1373,869 R_{o}+227914,938 r^{2}-17399,748 z^{2}-158262,452 C^{2}-88475,754 R^{2} \text {. } \\
& R=0,0385-0,833 r-0,0072 z-0,347 C, \\
& \delta_{u, \min }=\sqrt{\frac{36 v_{c} \mu R_{o}}{2,5 v_{H}^{2} \rho_{u}}} \\
& \tau=\frac{R_{2}-R_{1}}{v_{c}}=\frac{V_{2}}{Q_{2}}=\pi H \frac{R_{2}-R_{1}}{Q_{2}}, \\
& \tau=\pi H \frac{R_{o}}{Q_{2}} \\
& v_{c}=\frac{Q_{2}}{\pi H R_{o}} \\
& K_{c}=\frac{v_{c} \tau}{\lambda}, \\
& \lambda=R_{u}-R_{o}, \\
& K_{c}=\frac{G_{2} \tau R_{u}}{\pi H}, \\
& \phi=\frac{G_{2}-K_{c}}{G_{2}} 100 .
\end{aligned}
$$

PERIÓDICO TCHÊ QUÍMICA•www.periodico.tchequimica.com • Vol. 15 N. 30. • ISSN 1806-0374 (impresso) • ISSN 1806-9827 (CD-ROM) • ISSN 2179-0302 (meio eletrônico) 